\title{
TRABALHO E EDUCAÇÃO NA PERSPECTIVA DOS ORGANISMOS MULTILATERAIS ${ }^{1}$
}

\author{
Work and education from the perspective of multilateral organizations
}

\author{
LEITE, Valter de Jesus² \\ BORGES, Liliam Faria Porto ${ }^{3}$ \\ FAUSTINO, Rosângela Celia ${ }^{4}$
}

\begin{abstract}
Resumo
Evidencia os interesses dos organismos multilaterais na interface trabalho e educação por trás da retórica de combate e eliminação da pobreza. A metodologia utilizada foi um levantamento documental das produções e relatórios dos organismos multilaterais compreendidos enquanto desdobramento da Conferência Mundial sobre Educação Para Todos (1990), assim como, a revisão bibliográfica de autores que debatem a temática. Verifica-se nos documentos a análise da relação entre trabalho e educação sob a égide do combate e eliminação da pobreza e, a educação assume, assim, um caráter salvacionista. A orientação das reformas educacionais se dá em face da dinâmica do capital prover as necessidades básicas de aprendizagem, competências, habilidades e qualificações necessárias para o desenvolvimento econômico e social, na busca de uma suposta equidade social. Ancorada no binômio pobreza-segurança, a veemência da política-ideológica e de seu direcionamento de reformas estruturais nas políticas educacionais está na pretensão de combater a pobreza por propiciar clima desfavorável aos negócios. Nessa perspectiva, a educação colabora na sustentação do controle político da burguesia mundial sobre os processos educativos direcionados para reestruturação produtiva na divisão internacional do trabalho. O trabalho permite concluir que a interface "educação e trabalho" nesta perspectiva, assume um caráter pragmático e unidimensional para formação de recursos humanos - 0 chamado Capital Humano.
\end{abstract}

Palavras-chave: Organismos multilaterais. Trabalho e educação. Capital Humano.

\begin{abstract}
It highlights the interests of multilateral organizations in the interface work and education behind the rhetoric of combat and eliminating poverty. The methodology used was a documentary survey of the productions and reports of multilateral bodies comprised understood as an unfolding of the World Conference on Education for All (1990), as well as the bibliographic review of authors who discuss the thematic. It is verified in the documents the analysis of the relationship between work and education under the aegis of combat and elimination of poverty and, education assumes, thus, a salvationist character. The orientation of educational reforms occurs in the face of the dynamics of capital to provide basic learning, needs skills and competences and necessary qualifications for economic and social development in the pursuit of a supposed social equity. Anchored in the binomial of poverty-security, the
\end{abstract}

\footnotetext{
${ }^{1}$ Coordenação de Aperfeiçoamento de Pessoal de Nível Superior - Capes, Brasil. Processo no 88882.449079/2019-01 do Programa DS.

${ }^{2}$ Doutorando em Educação pela Universidade Estadual do Oeste do Paraná (UEM), Mestre em Educação pela Universidade Estadual do Oeste do Paraná (Unioeste), Especialista em Trabalho, Educação e Movimentos Sociais pela Escola Politécnica de Saúde Joaquim Venâncio (EPSJV-FIOCRUZ/PRONERA). Licenciado em Pedagogia pela Unioeste. Bolsista da Coordenação de Aperfeiçoamento de Pessoal de Nível Superior - Capes, Brasil. Processo no 88882.449079/2019-01 do Programa DS. Atua na Coordenação Política Pedagógica das Escolas Itinerantes do MST Paraná. E-mail: valterleitemstpr@gmail.com.

${ }^{3}$ Doutora em Educação pela Universidade Federal de São Carlos (2006). É professora Associada B da Universidade Estadual do Oeste do Paraná, vinculada ao Centro de Educação, Comunicação e Artes - CECA. Atua nos cursos de pedagogia e nas licenciaturas. E-mail: liliamfpb@gmail.com.

${ }^{4}$ Doutora em Educação pela Universidade Federal de Santa Catarina (UFSC). Professora do Curso de Pedagogia e do Programa de Pósgraduação em Educação (PPE) da Universidade Estadual de Maringá. Coordenadora do Grupo de Pesquisa em Educação Indígena no Paraná. E-mail: rcfaustino@uem.br.
}

Trabalho \& Educação | v.30 | n.1 | p.161-175 | jan-abr | 2021 
vehemence of the political-ideological and its direction of structural reforms in the educational policies is in the pretense of combating poverty by providing unfavorable business climate. In this perspective, education collaborates in sustaining the political control of the world bourgeoisie about the educational processes directed towards productive restructuring in the international division of labor. The work allows to conclude that the interface "education and work" in this perspective, assumes a pragmatic character and human resources formation - the so-called human Capital.

Keywords: Multilateral organizations. Work and education. Human capital.

\section{INTRODUÇÃO}

O conjunto categorial deste artigo se encontra enraizado no entendimento de que 0 trabalho é ontológico ao ser humano, sua essência, sua possibilidade de existir enquanto ser diferenciado da natureza, conforme Marx e Engels (2007) e Engels (1986). A partir deste pressuposto teórico, reconhece-se que o distanciamento da determinação animal é o mesmo movimento de constituir-se ser humano e assim, é o acúmulo de saberes e práticas advindas do trabalho que conforma a humanidade - individual, social e historicamente.

Desse pressuposto - do trabalho enquanto humanização - avançamos para a compreensão de é pela educação que se faz o caminho de apropriação dos elementos que definem qual trabalho e quais parâmetros de produção da vida. Assim, afirmamos que a apreensão dos conhecimentos sistematizados pelos homens em seu caminho histórico é riqueza humana e determina a humanização.

Em contraposição a esse pressuposto, particularmente sintetizado por Saviani (2005), temos um entendimento de que, na sociedade de classes, e principalmente, no modo de produção capitalista, onde absolutamente tudo se converte em mercadoria, é importante acompanhar, de que modo, a proposição de políticas educacionais formulam, pela educação, a conversação da humanização em ferramenta que permita ampliar a acumulação, secundarizando o que é central - a ampliação da existência humana livre e crescentemente distanciada do que the determina a condição de ser natural.

Este trabalho, construído com base nos pressupostos teóricos aqui indicados e por meio de revisão bibliográfica e análise documental, procura apresentar como os organismos internacionais e multilaterais, a serviço da acumulação do capital, convertem a educação escolar em uma de suas eficientes ferramentas.

\section{A ARMAdilha NA RETÓRICA DE COMBATE E ELIMINAÇÃo DA POBREZA}

O Capitalismo nas suas diferentes fases vem buscando a criação de instrumentos e mediações que potencializam a subordinação da força humana em função a satisfação da elevação de produção de capital em detrimento da vida humana. Ainda que, em seu discurso, apregoe 0 atendimento às necessidades humanas, o cenário histórico demonstra que, a cada dia, amplia o submetimento de grande parte da população à condições desumanas.

Com o desenvolvimento do capitalismo e o jogo econômico globalizado, pós Segunda Guerra Mundial, paulatinamente amplia-se a subordinação dos países periféricos aos centros hegemônicos do capital, particularmente os Estados Unidos da América - EUA, caracterizado pelo crescente desenvolvimento desigual amparado pela exploração da força de trabalho da maioria da população. 
Neste cenário, em decorrência da Conferência de Bretton Woods, que objetivou constituir acordos para criar um sistema de regras, instituições e procedimentos para estruturar a ordem econômica e a política internacional, surgem instituições com a finalidade de para financiar a reconstrução e desenvolvimento dos países destruídos pela segunda Guerra Mundial. A partir de 1949 amplia sua abrangência para o financiamento do desenvolvimento econômico e social dos países do denominado Terceiro Mundo, projetos estrategicamente focalizados na infraestrutura, com condicionalidades econômicas designadas pelos agentes financiadores, conforme Leher (1999).

Neste ensejo, o Banco Mundial (2001) se constitui enquanto instituição que financia e oferece empréstimos internacionais para os ditos países em desenvolvimento, e é composto por cinco organismos internacionais: 1) Banco Internacional para Reconstrução e Desenvolvimento (BIRD); 2) Associação Internacional de Desenvolvimento (AID); 3) Sociedade Financeira Internacional (SFI); 4) Agência Multilateral de Garantia de Investimentos (MIGA); e 5) Centro Internacional para Arbitragem de Disputas sobre Investimentos (CIADI) (DEITOS, 2011; PRONKO, 2014). Tais organismos atuam em diferentes frentes de trabalho que se complementam com 0 objetivo de reduzir a pobreza e promover o desenvolvimento sustentável.

Na gestão presidencial do Banco Mundial de Robert S. McNamara (1968-1981), "[...] anteriormente secretário de Defesa dos Estados Unidos (1961-1968) [...]" (LEHER, 1999, p. 21), o binômio pobreza-segurança desloca-se para centralidade dos projetos do Banco Mundial.

De acordo com Pronko e Neves (2008), o binômio pobreza-segurança adquire diferentes formas até os dias de hoje, mas desde a dívida externa de 1982, justificam empréstimos que anteriormente visavam garantir cumprimento de metas macroeconômicas e setoriais em prol da modernização capitalista, o que desde as reformas preconizadas pelo Consenso de Washington passa a vincular os empréstimos "[...] ao ajuste estrutural com vistas a preparar seus países-membros para a participação cada vez mais orgânica no mundo em transformação" (PRONKO \& NEVES, 2008, p.95). Nessa conjuntura social e econômica os países apelam ao Banco Mundial por financiamento de projetos para administrar sua situação e criar abertura do mercado internacional em prol da economia.

Trata-se de medidas que integram uma reestruturação capitalista cunhada pelo Banco Mundial e o FMl com incidência na reforma da aparelhagem estatal e da estrutura e dinâmica da sociedade civil com base no americanismo enquanto fundamento ideológico de produção material e simbólica da vida, afirmam Pronko e Neves (2008).

Neste cenário de reordenamento do capital, de controle ideológico e de atenuação das desigualdades à luz do binômio pobreza-segurança, a partir do redirecionamento das prioridades do Banco Mundial nos marcos da década de 1960 a educação escolarizada ocupa posição estratégica enquanto instrumento de combate à pobreza.

Para isso, modificou o escopo dos projetos, ampliando-se para programas (muito mais complexos e abrangentes, incidindo sobre setores vastos como educação, tornando mais rígidas as condicionalidades). Esta reorientação do banco obteve êxito, não tanto pelo sucesso das políticas setoriais, que em geral fracassaram economicamente e socialmente, mas em termos políticos mais amplos (LEHER, 1999, p. 23).

Desde então altera - se a forma de pensar e agir do Banco Mundial, este passa a atuar definitivamente no setor social, especialmente na educação, saúde e produção agrícola. 
Tal modificação na centralidade das preocupações do Banco Mundial é justificada pela tese de McNamara, que a educação e saúde são fundamentais para ampliação da produtividade da população marginalizada, fundamentalmente para a segurança nacional, tendo em vista que a pobreza significava uma ameaça para a economia das nações desenvolvidas, considerando serem, os pobres, sensíveis e propensos ao comunismo. É preciso considerar que o acesso à saúde e à educação, ou à políticas sociais em geral, são caminhos de ampliação de atendimento à classe trabalhadora no que diz respeito ao acesso à direitos fundamentais e que, contraditória e dialeticamente, fortalecem no mesmo movimento, o Estado capitalista. Com isto, o Banco Mundial voltase "[...] por meio de escolas técnicas, programas de saúde e controle de natalidade, ao mesmo tempo em que promove mudanças estruturais na economia desses países, como a transposição da "revolução verde para o chamado Terceiro Mundo (LEHER, 1999, p. 22).

As primeiras intervenções do Banco no âmbito educacional objetivaram o "[...] incremento do ensino técnico-vocacional e da educação superior para formar mão-deobra especializada com vistas a acelerar o desenvolvimento da industrialização e impulsionar a mecanização do campo" (PRONKO \& NEVES, 2008, p. 97).

Com estas estratégias de reorganização do capital, a partir da década de 1970, com as orientações propagadas pelo Consenso de Washington, o Estado sofre grandes interferências dos organismos multilaterais no redirecionamento das Políticas Públicas, com base em medidas de ajuste estruturais voltadas para a reforma financeira, a liberalização do comércio, a reforma da previdência, a privatização das empresas estatais e a reforma trabalhista (WILLIAMSON, 1992; PRONKO \& NEVES, 2008).Com isto, as políticas externas constituídas pelo Banco Mundial, e potencializadas pelo Consenso de Washington, ampliaram as condições para mercantilização dos direitos fundamentais, aumentando a participação da iniciativa privada em diferentes setores, exigindo do Estado uma atuação de atenuação das contradições entre as classes com políticas paliativas. A prioridade dos gastos públicos deve voltar-se "[...] para áreas negligenciadas com alto retorno econômico e potencial para melhorar a distribuição de renda, como saúde, educação e infraestrutura" (WILLIAMSOM, 1992, p. 44).

O Banco Mundial e o FMl afirmam a necessidade da desregulamentação do Estado como meio controlar suas instituições, disciplinar seus agentes para subordiná-los aos seus interesses e, sobretudo, abrir as portas ao empresariado, conforme Deitos (2010). O papel do Estado passa a ser de organizador de um ambiente satisfatório para 0 mercado, ao deliberar que os Estados devam

[...] extinguir regulamentação que impeçam a entrada de novas firmas ou que restrinjam a competição e assegurar que toda a regulamentação seja justificada por critérios tais como segurança, proteção ao meio ambiente ou uma supervisão prudente de instituições financeiras (WILLIAMSON, 1992, p. 45).

Por dentro destas reformas, a educação exerce, para o Banco Mundial, o papel estratégico no acúmulo de capital humano para alavancar o crescimento econômico, tal como evidencia o Informe Anual do Banco Mundial de 1993: "[...] o trabalho é a principal propriedade do pobre, o incremento na oferta e qualidade da educação representa um mecanismo-chave para redução de grandes desigualdades e reduzir o número de pessoas na pobreza" (PRONKO\& NEVES, 2008, p. 98). 


\title{
A DEFINIÇÃo do PAPEL DA EDUCAÇÃo ESCOLAR PELOS ORGANISMOS ECONÔMICOS MULTILATERAIS
}

O interesse do Banco Mundial na relação da educação com o trabalho, além de em face da dinâmica do capital prover os conhecimentos, habilidades e qualificações necessárias para o desenvolvimento econômico e social, a veemência de sua intervenção, encontrase, essencialmente, no conteúdo político-ideológico por trás do binômio pobrezasegurança. A doutrinação política-ideológica, pelo viés educacional, fica evidente ao priorizar a atuação no setor educacional com vistas ao combate à pobreza por considerarem que esta pode propiciar ímpetos à situação política e criar clima desfavorável aos negócios:

\begin{abstract}
As conexões entre educação, segurança e pobreza fornecem o substrato das reformas educacionais em curso na América Latina. Com aprofundamento sem precedentes da polarização na década de 1990, o Banco Mundial dedica cada vez maior atenção à construção de instituições adequadas à era do mercado, de modo a ter recursos institucionais para 'manejar' as contradições do sistema. A educação é radicalmente modificada, tornando-se cada vez menos politécnica (no sentido conferido por Marx) e cada vez mais instrumental: os conteúdos estão fortemente carregados de ideologias apologéticas ao capital e o debate educacional é pautado em grande parte pelos 'homens de negócios' e pelos estrategistas políticos (LEHER, 1999, p.29).
\end{abstract}

Neste cenário, a década de 1990 fica marcada pela grande investida e ajuste do sistema e de políticas educacionais, com participação do empresariado e da sociedade, amparadas e originada pelo processo de globalização em curso que determina transformações econômicas, sociais e políticas em função das novas estratégias do neoliberalismo e do capital. Amplia-se a presença dos organismos multilaterais e empresariais com centralidade na educação, "[...] entram em cena em termos organizacionais e pedagógicos, marcados por grandes eventos, assessorias técnicas e farta produção documental" (FRIGOTTO, CIAVATTA,2003, p.97), especialmente na educação básica por ser o nível educacional que assegura as condições mínimas da força de trabalho, formação de recursos humanos com base nos princípios da divisão social do trabalho, como indicado por Moraes (2011).

A primeira grande expressão deste movimento, a partir da década de 1990, foi a Conferência Mundial sobre Educação para Todos ${ }^{5}$, ocorrida entre os dias 05 e 09 de março de 1990, em Jomtien - Tailândia, que disseminou um projeto de educação em nível mundial representando um estratégico marco do novo papel que a educação desempenharia para no decênio de 1990 no desenvolvimento do capitalismo globalizado (FRIGOTTO \& CIAVATTA, 2003). Também conhecida como Conferência de Jomtien e Conferência Geral da Unesco, sua principal ideia foi se comprometer com a meta da Educação Primaria Universal sob a tese da satisfação das necessidades básicas de aprendizagem.

A conferência de Jomtien reuniu representantes de 155 governos e diversas agências internacionais e organizações não governamentais, os quais subscreveram e aprovaram a Declaração Mundial sobre Educação para Todos: satisfação das necessidades básicas de aprendizagem Jomtien (1990), comprometendo-se em assegurar a universalização de uma "educação básica de qualidade" (FRIGOTTO \& CIAVATTA, 2003, p.98) que a

\footnotetext{
${ }^{5}$ Financiada pelas agências internacionais como a UNESCO, UNICEF, PNUD e Banco Mundial 
despeito do projeto indicar os interesses do capital, na contradição possibilitou programas robustos de escolarização das massas.

Em decorrência da Conferencia de Jomtien, uma série de outros encontros e reuniões dos organismos multilaterais se constituíram nos anos 1990, resultando um conjunto de documentos sobre educação, aos quais foram configurando a concepção, diretrizes e reformas na educação dos países de terceiro mundo para o século XXI, entre elas em 1991 a reunião da Comissão Internacional sobre Educação para o Século XXl6 que resultou no Relatório Jacques Dellors, denominado Educação: um tesouro a descobrir, no ano de 1993 em Nova Delhi, na India. Naquela ocasião reuniram-se os países de maior população no mundo (Indonésia, China, Bangladesh, Brasil, Egito, México, Nigéria, Paquistão e Índia) para reiterar o compromisso com as metas da Conferência de Jomtien (UNESCO, 1998), conforme expresso na Declaração de Nova Delhi sobre Educação para Todos (UNESCO, 1998); Reuniões do Projeto Principal de Educação para a América Latina e Caribe - PROMEDLAC, financiadas pela UNESCO que tiveram seus primeiros encontros no México (1984), em Bogotá (1987), na Guatemala (1989), e depois adquire maior evidencia em Quito (1991) com a consagração da Educação para Todos, ocasião que adota-se a estratégia disseminada pela CEPAL no documento Transformação produtiva com equidade (CEPAL, 1990). Na sequência, em Santiago (1993) novo encontro que resulta na Declaração de Santiago que adota o Plano de Ação estabelecido pela Conferência de Jomtien , em Kingston (1996) e em Cochabamba (2001) resulta na Declaração de Cochabamba: Educação para todos: cumprindo nossos compromissos coletivos, legitimada pelos Ministros da Educação da América Latina e do Caribe reiterando o compromisso com as seis metas da Educação para Todos deliberadas no Fórum Mundial de Dakar ${ }^{7}$, em abril de 2000 (UNESCO, 2001). Esse fórum publica o documento Educação para Todos: O Compromisso de Dakar (Marco da Ação de Dakar) (SHIROMA, 2002; OREALC,1993); que se soma aos diversos relatórios e documentos do Banco Mundial principal sujeito nas reformas educacionais voltadas ao mercado 8 .

Em termos gerais esse conjunto de reuniões e documentos organizados pelos organismos multilaterais para direcionar as reformas educacionais sob a retórica Educação para Todos, "[...] faz recomendações de conciliação, consenso, cooperação, solidariedade para enfrentar as tensões da mundialização, a perda das referências e de raízes, as demandas de conhecimento científico-tecnológico [...]" (FRIGOTTO;CIAVATTA, 2003, p. 99), essencialmente acerca das tecnologias de informação, tendo a educação como instrumento fundamental para desenvolver nos indivíduos a capacidade de responder aos desafios.

Assim, o projeto de reformas define suas metas e concepções pedagógicas a ela atreladas negando a apropriação dos conhecimentos científicos e a decorrente humanização dos sujeitos como fim dos processos educativos. Ainda que,

6 Convocada a mando da Conferência Geral da UNESCO, pelo Diretor Geral Frederico Mayor o qual solicitou a Jacques Delors para assumir a presidência dessa Comissão, que reuniu outras 14 personalidades de todas as regiões do mundo, oriundas de diversos horizontes culturais e profissionais (DELORS, 2010, p.39).

\footnotetext{
${ }^{7}$ Contou com a participação de 180 países e 150 Organizações não governamentais.

${ }^{8}$ Não serão objeto de análise todos os documentos citados, mas serão priorizados aqueles que acreditamos ter cumprido estruturante papel na orientação das reformas educacionais.
} 
contraditoriamente, a classe trabalhadora acesse parcialmente esse conhecimento, seu sentido passa a ser para os fins da acumulação.

O Banco Mundial, ao disseminar o papel da educação em dar respostas ao mercado produtivo e o crescimento econômico, reforça a ideia de educação como redentora, como instrumento no combate à pobreza. Por considerarem que a pobreza propicia riscos à situação política e criar clima desfavorável aos negócios, Frigotto e Ciavatta (2003); Leher, (1999) reafirmam tal necessidade, na medida em que o desenvolvimento tecnológico exige melhores capacidades cognitivas dos seus operadores. (No interior desta retórica designam a viabilização de empréstimos com intuito de reduzir a pobreza e qualificar o nível de vida com desenvolvimento sustentável e investimento na educação e saúde básica para fortalecer o capital humano, conforme relatórios do Banco Mundial (1995 e2001).

É neste marco da relação entre capital, trabalho e educação que o Banco Mundial atua estrategicamente para garantir simultaneamente, a alargada produção de capital e a reprodução das relações dominantes burguesas sobre os países periféricos. Seu caráter de compensação concernente à educação se revela na articulação pretendida dos processos educacionais com a elevação da produtividade e capital, combinada ao controle ideológico por meio de uma concepção de educação utilitarista e economicista. Conforme podemos constatar no próprio relatório do Banco Mundial O Combate à Pobreza no Brasil: Relatório sobre Pobreza $n^{\circ}$ 20475-BR ao tratar da possibilidade de redução da taxa de pobreza no Brasil, apresentam enquanto estratégia, entre outras metas, a da capacidade de fortalecer e valorizar os recursos disponíveis para os pobres nos seguintes termos:

Os recursos dos pobres ficariam mais valorizados mediante uma melhoria na educação, na saúde, nos serviços físicos e urbanos, e no capital físico. Os pobres que tiverem mais ativos poderão aproveitar melhor as oportunidades econômicas (BANCO MUNDIAL, 2001, p.12).

A interface da educação com o mercado de trabalho é eixo orientador das reformas educacionais na busca por uma suposta equidade social, articula em sua estratégia a restruturação produtiva do capitalismo com a imposição política- ideológica no direcionamento das políticas educacionais de formação para o trabalho sob a égide do capital, conforme Frigotto (2007). Para tal, a "[...] estratégia do Banco Mundial para a redução da pobreza se concentra na promoção do uso produtivo do trabalho, que é o principal ativo dos pobres, e na prestação de serviços sociais básicos aos necessitados" (BANCO MUNDIAL, 1995, p. 1).

Como nos ensina Marx, (1996) no Modo de Produção Capitalista, toda riqueza se transforma em mercadoria, muito especialmente a força de trabalho, motor de toda produção. Assim, na acepção de capital humano elaborada no século XX pelos economistas neoclássicos da Universidade de Chicago, entre eles Theodore Schult (1902-1998) e Gary Becker (1930-2014), é fundamentalmente necessária a manutenção da classe trabalhadora, recurso humano para se tomarem mais rentáveis e subordinados ao desenvolvimento do capital, conforme Leher (2010).

\section{A teoria do Capital humano e as proposições em políticas EDUCACIONAIS NOS RELATÓRIOS DAS AGÊNCIAS INTERNACIONAIS}


Abre-se aqui, um preâmbulo acerca da natureza da Teoria do Capital Humano, que tem sua gênese no século XVII na formulação do economista Adam Smith (1723-1790), ao disseminar a ideia de que o Estado devesse investir na formação do trabalhador para exploração de sua força de trabalho e, ao constatara uniformidade de sua vida estacionária corrompe naturalmente também a coragem de sua mente. [...] Ela destrói mesmo a energia de seu corpo e o incapacita a empregar suas forças com vigor e perseverança[...]" (SMITH apud MARX, 1996, p. 476). Com esta preocupação acerca da mutilação da mente do trabalhador e a perda de mão de obra, Smith propõem que

\begin{abstract}
Com gastos muito pequenos, o Estado pode facilitar, encorajar e até mesmo impor a quase toda a população a necessidade de aprender os pontos essenciais da educação, isto é, ler, escrever e calcular (...) Este tipo de atividade é geralmente muito simples e uniforme para dar-Ihes pequenas oportunidades de exercitarem a mente; ao mesmo tempo, seu trabalho é tão constante e pesado que lhes deixa pouco lazer e menos inclinação para aplicar-se a qualquer outra coisa, ou mesmo para pensar nisso. Embora, porém, as pessoas comuns não possam, em uma sociedade civilizada, ser tão bem instruídas como as pessoas de alguma posição e fortuna, podem aprender as matérias mais essenciais da educação — ler, escrever e calcular - em idade tão jovem, que a maior parte, mesmo daqueles que precisam ser formados para as ocupações mais humildes, têm tempo para aprendê-las antes de empregar-se em tais ocupações (SMITH, 1996, p. 246).
\end{abstract}

Em repúdio a esta ideia, Marx (1996), ao tecer a crítica à divisão do trabalho e à manufatura afirma que "A fim de evitar a degeneração completa da massa do povo, originada pela divisão do trabalho, A. Smith recomenda o ensino popular pelo Estado, embora em doses prudentemente homeopáticas" (MARX, 1996, p.476). Ou seja, Smith, na sua proposição, objetiva socializar o suficientemente para manutenção das condições necessárias de dominação de uma classe sobre outra, em mínimos necessários amoldar o trabalhador à divisão social do trabalho e conservar a ordem social capitalista.

A teoria do capital humano é um dos componentes que orienta o Banco Mundial e outros organismos multilaterais para intervenção na formação escolar em preparação para o trabalho produtivo, nesta formulação compreende-se a educação como meio de tornar os indivíduos capacitados, com competências e habilidades que os tornam mais rentáveis na lógica capitalista, aqui educação e formação de produto-recurso humano torna-se predicado para ser comercializado em consonância as exigências do mercado, faz da empregabilidade uma qualidade para tornar o indivíduo uma força de trabalho mais vendável no mercado, afirma Leher (2010).

Este sentido da educação instituiu-se como crucial para a lógica do capitalismo neste tempo histórico, com vistas ao planejamento e progresso econômico. Segundo Schultz (1971) compreender a educação a partir da teoria do capital humano permitiu mobilizar o mercado.

[...] para uma especificação mais completa de mensuração e acumulação de capital moderno. Fez, também, com que nos tornássemos mais conscientes das mudanças que se registraram na qualidade do capital material. Desta forma, o fato de tratar a educação como capital humano nada mais é senão um passo à frente rumo a uma captação consciente de todo o capital (SCHULTZ, 1971, p. 130).

Tal como podemos evidenciar no documento Prioridades y estrategias para la educación - Examen del Banco Mundial (1995), ocasião em que fundamenta a lógica de investir na educação como forma valorizar o capital humano utilizando-se de um dos economistas formuladores da teoria do capital humano: 
As novas teorias sobre o crescimento económico, como o velho, demonstram a complementaridade de capital humano e físico: um conjunto maior de capital humano aumenta o valor de arrendamento das máquinas; aumentando reserva de capital físico melhora a eficiência do investimento na educação e investimento em geral tem pouca influência sobre o crescimento económico, quando ele não é suportado pela educação (Lucas 1988; Becker 1964) (BANCO MUNDIAL, 1996, p. 26).

E novamente reitera a formação de recurso humano ao mencionar o papel que a educação básica deve exercer com vistas a empregabilidade, neste sentido para o Banco Mundial (1996) a

Educação básica fornece os conhecimentos, habilidades e atitudes para funcionar eficazmente na sociedade. Competências básicas em áreas gerais, tais como a expressão oral, conhecimentos de informática, habilidades de comunicação e resolução de problemas pode ser aplicado em uma ampla gama de ambientes de trabalho e pode permitir que as pessoas adquiram habilidades e conhecimentos específicos para o emprego no local de trabalho (Becker 1964) (BANCO MUNDIAL, 1995, p. 107).

Assim, os organismos multilaterais e seus diferentes documentos mencionados acima, adotam a estratégia que compreende a educação como

[...] uma ferramenta importante para o desenvolvimento econômico e social. É um elemento crucial da estratégia do Banco Mundial para ajudar os países a reduzir a pobreza e melhorar os padrões de vida através de um crescimento sustentável e investimento em capital humano. Este exige dupla estratégia que promove o uso produtivo de trabalho, que é o principal trunfo dos pobres, e a prestação de serviços sociais básicos aos pobres (BANCO MUNDIAL, 1995, p. 21. grifos nossos).

Destarte, para alcançar a elevação da produtividade esperada instituem o direcionamento da educação minimalista de forma que corresponda as necessidades do mercado, conforme designado pela Declaração Mundial sobre Educação para Todos: satisfação das necessidades básicas de aprendizagem Jomtien (1990), categoriza-se necessidades fundamentais tanto os

[...] instrumentos essenciais de aprendizagem (leitura, escrita, expressão oral, cálculo, resolução de problemas), quanto aos conteúdos educativos fundamentais (conhecimento, aptidões, valores, atitudes), indispensáveis ao ser humano para sobreviver, desenvolver suas capacidades, viver e trabalhar com dignidade, participar plenamente do desenvolvimento, aprimorar sua qualidade de vida, tomar decisões ponderadas e continuar a aprender (JOMTIEN, 1990, p.1. grifos nossos).

Ainda nesta declaração, em seu artigo 3, denominado Universalizar o acesso à educação e promover a equidade, destaca: "Para que a educação básica se torne equitativa, é mister oferecer a todas as crianças, jovens e adultos, a oportunidade de alcançar e manter um padrão mínimo de qualidade da aprendizagem" (JOMTIEN, 1990, p.1. grifos nossos).

Correspondendo a estas reflexões o relatório Educação: um Tesouro a Descobrir adota "[...] o que foi tão bem definido, por ocasião da Conferência de Jomtien, em 1990, sobre a educação básica e as necessidades educativas fundamentais, define princípios intitulados "Os quatro Pilares da Educação: aprender a conhecer, aprender a fazer, aprender a conviver e aprender a ser" (DELORS, 2010), que tem como finalidade "[...] a construção de capacidades que permitam orientar a ação de cada um, como membro de uma família, cidadão ou como um produtivo membro da sociedade" (DELORS, 2010, p.10). 
Indica-se como essa tradição vem também do pensamento educacional mais estrito, como em Dewey (1979) ao defender que assegurar igualdade de oportunidade de acesso à educação para todos basta para cada indivíduo alcançar melhores condições de vida, desde que se dedique individualmente a partir de sua aptidão, sendo a escola o instrumento social para socializar os indivíduos combinado ao desenvolvimento produtivo da sociedade. E como preconizou Durkheim (1858-1917) a educação como forma de socialização do conhecimento necessário para reprodução, manutenção, integração e adaptação dos sujeitos subordinada a ordem social vigente com intuito de favorecer o progresso econômico e social burguês (DURKHEIM, 2011).

É esta perspectiva individualista e meritocrática que sustenta os Quatro Pilares da Educação (DELORS, 2010), de socializar a escola para a exploração do trabalho. Aprender a conhecer diz respeito as atividades de aprendizado voltada aos conteúdos e informações instrumentais que a vida e o trabalho imediato exigem. "Este tipo de aprendizagem que visa não tanto a aquisição de um repertório de saberes codificados, mas antes o domínio dos próprios instrumentos do conhecimento [...]" (DELORS, 2010, p. 90", por isso "[...] aprender a aprender, exercitando a atenção, a memória e o pensamento [...]" (DELORS, 2010, p.92).

Aprender a fazer trata-se de "[...] como ensinar o aluno a pôr em prática os seus conhecimentos e, também, como adaptar a educação ao trabalho futuro [...]" (DELORS, 1998, p.93). Vincula-se estreitamente à formação para o trabalho em vistas da elevação de produtividade, supervaloriza o ensino de competências de acordo as exigências do empresariado para facilitar operação dos trabalhos, "[...] muitas vezes denominadas "saber-ser" pelos dirigentes empresariais, se juntam ao saber e ao saber-fazer para compor a competência exigida [...] (DELORS, 2010, p. 94),

\begin{abstract}
Os empregadores substituem, cada vez mais, a exigência de uma qualificação ainda muito ligada, a seu ver, à ideia de competência material, pela exigência de uma competência que se apresenta como uma espécie de coquetel individual, combinando a qualificação, em sentido estrito, adquirida pela formação técnica e profissional, o comportamento social, a aptidão para o trabalho em equipe, a capacidade de iniciativa (DELORS, 2010, p.94. Grifos nossos).
\end{abstract}

Prioriza-se conteúdos específicos em função da organização de determinado trabalho, e por isso a ideia de orientar o processo educativo escolar a luz das competências ${ }^{9}$ exigidos no mundo produtivo e o reordenamento dos conteúdos de trabalho para adaptação dos sujeitos à nova sociabilidade do capital, tal como proposto por Adam Smith, oferecer o mínimo suficiente para participarem da sociedade pelo processo produtivo, ou seja, para que se cumpra o papel reservado aos trabalhadores na lógica do capital - qual seja, produzir a riqueza.

Jaques Delors apresenta que os Quatro Pilares articulados, supostamente concebe uma "educação como um todo", sem privilegiar outros conhecimentos em detrimento de outras formas de aprendizagem (DELORS, 2010, p. 102). Mas analisando os dois pilares acima nota-se desdobramentos de conteúdos para "satisfação das necessidades de aprendizagem" que persistem na integração dos indivíduos na sociedade com vistas à elevação de produtividade e a nova sociabilidade exigida pelo capital que subordina o trabalho ao capital como orienta a sociedade do conhecimento.

\footnotetext{
${ }^{9}$ Ver Ramos, M. N. Pedagogia das competências: autonomia ou adaptação? São Paulo: Cortez, 2001.
} 
A Declaração de Nova Delhi, em perfeita harmonia com esta lógica, reitera a definição de conteúdos mínimos, instrumentais e módicos, condicionados à empregabilidade a qual apresenta como referência para deliberar os conteúdos, os problemas mais urgentes do capital, ao anunciar que

[...] os conteúdos e métodos de educação precisam ser desenvolvidos para servir às necessidades básicas de aprendizagem dos indivíduos e das sociedades, proporcionandoIhes o poder de enfrentar seus problemas mais urgentes - combate à pobreza, aumento da produtividade, melhora das condições de vida [...] (DELHI, 1998, p.2).

Não obstante, a Declaração do Marco de Ação de Educação Para Todos de Dakar, amparada essencialmente na Declaração de Jomtien (1990), reafirma o comprometimento assinalado nos outros documentos, com [...] uma educação que satisfaça suas necessidades básicas de aprendizagem, no melhor e mais pleno sentido do termo, e que inclua aprender a aprender, a fazer, a conviver e a ser" (DAKAR, 2001, p.8). Afim, de "[...] providenciar alívio e/ou cancelamento da dívida em tempo mais curto e de forma mais ampla para reduzir a pobreza, e com forte compromisso na educação básica" (DAKAR,2001, p. 10).

Passados uma década da Conferência de Jomtien e com a ausência de êxito nas metas instituídas pelos organismos multilaterais, ampliam a abrangência temporal, portanto, "[...] Os governos têm a obrigação de assegurar que os objetivos e as metas da Educação para Todos sejam alcançados e mantidos. [...] por meio de amplas parcerias no âmbito de cada país, apoiada pela cooperação com agências e instituições regionais e internacionais" (DAKAR, 2001, p.8), escancarando as portas para ampliar a iniciativa privada na educação, a partir das organizações não governamentais com a parceria público-privado (RABELO; SEGUNDO; JIMENEZ, 2009).

Por último, observa-se na Declaração de Cochabamba (2001) fruto da Reunião do Projeto Principal de Educação para a América Latina e Caribe - PROMEDLAC, novamente a tese da educação redentora, em que as "[...] pessoas são excluídas dos benefícios do desenvolvimento econômico e social que acompanham a globalização, porque são afetadas por limitações na sua educação que as impede de participar ativamente nesse processo (COCHABAMBA, 2001, p. 1).

Outra vez a contenção de pobreza tendo como pano de fundo o intuito do controle político-ideológico se apresenta como eixo norteador para assegurar Educação Para Todos e responder ao mercado produtivo. Reitera a Declaração de Cochabamba, que os valores devem assegurar maior importância nos processos educacionais, necessitando promover a educação por toda a vida dentro de ambientes humanos e educacionais múltiplos e interativos. "Queremos que a nossa educação se fortaleça mediante uma firme fundamentação na possibilidade do aprender a ser, fazer, conhecer e viver em conjunto" (COCHABAMBA, 2001, p. 2).

Ao retomar os Quatro Pilares da Educação de Jaques Delors, observe-se mais uma vez a supervalorização dos valores e competências em detrimento do conhecimento universal acumulado pela humanidade, tendo os conteúdos definidos pelo "saber-ser" e saber-fazer conforme ditam os empresários para compor a competência exigida (DELORS, 2010, p.94), desta forma, 
A opção de estimular formas novas e flexíveis de aprendizado representa uma resposta no que diz respeito aos jovens e adolescentes que vivem na pobreza e na exclusão - aqueles que abandonaram a educação formal sem ganhar acesso a uma educação de qualidade. $A$ realidade do atual mercado de trabalho, em um contexto de poucas oportunidades para 0 emprego formal, exige o treinamento para o emprego, superando obstáculos para assegurar uma transição efetiva do sistema escolar para o emprego (COCHABAMBA, 2001, p.4. grifos nossos).

De forma breve, poderíamos indicar que a seleção de conteúdos, motivada por tais objetivos, secundariza a possibilidade de uma educação humanizadora e desalienante, na medida em que, o acesso ao pensamento sistematizado oportuniza a compreensão da realidade e suas contradições, permite escolhas orientadas pela análise de interesses de classes e possibilita a superação da forma de intervir e produzir a reprodução social.

Ainda é merecido destacar o conteúdo do item 3 da Declaração de Santiago que ao tratar dos desafios da educação básica para jovens e adultos, apresenta a necessidade de associação com "[...] as demandas de modernização da produção, aos efeitos da crise econômica sobre os setores mais pobres e as novas competências individuais e sociais necessária para participar como cidadãos e consumidores [...] (SANTIAGO, 1993, p. 42).

Em 2011, o Grupo Banco Mundial lançou a nova estratégia para a educação, intitulada "Estratégia 2020 para a Educação: Aprendizagem para todos - Investir nos conhecimentos e competências das pessoas para promover o desenvolvimento". Justifica-se a nova estratégia na evolução "[...] sobretudo nos países em desenvolvimento, nas matrículas, na retenção escolar e na igualdade de gênero na escola, fruto da operacionalização da diretriz de "Educação para Todos" [...] e dos esforços nacionais para alcançar os Objetivos do Milênio" (PRONKO, 2015, p. 106).

$O$ documento salienta uma insuficiência nesses avanços frente aos desafios contemporâneos, exigindo o desenvolvimento de uma nova estratégia que conceba a educação para além da escolarização de modo que exerça e avance na educação como instrumento crucial no desenvolvimento econômico, portanto, que proporcione a aprendizagem das competências para todos. Para o Banco Mundial o motor do desenvolvimento "[...] será, em última análise o que as pessoas aprendem, dentro e fora da escola, desde o jardim-escola até o mercado de trabalho. A nova estratégia do Banco para 10 anos, procura alcançar este objetivo alargado de "Aprendizagem para Todos" (BANCO MUNDIAL, 2011, p. 01, grifos no original). Para alcançar esse objetivo o BM promove "[...] reformas nos sistemas de educação dos países e criando uma base global de conhecimento suficientemente forte para liderar estas reformas" (BM, 2011: 1, grifos no original).

Novamente expressa-se aqui a ideia de socialização na lógica do mercado de trabalho enquanto integração do sujeito ao trabalho subsumido pelo capital. A educação para o povo, nesta perspectiva, assume um caráter minimalista, assegurando treinamento instrumental ordenadas pelas competências básicas, menos complexas e esvaziadas de conhecimentos científicos e saberes possíveis de compreensão das contradições existentes nos processos sociais, conforme Moraes (1999) e Frigotto (2010).

[...] opera-se nesse contexto, um esvaziamento do conteúdo, em nome de um conjunto de habilidades, aptidões e valores apegados ao plano da imediaticidade e do utilitarismo, temperados com abstrações mistificadoras, deslocados de suas determinações ontológicas. Reeditam-se, em suma, concepções pedagógicas instrumentais e pragmáticas, em nome da adequação, em última análise, às demandas do mercado (RABELO et al, 2009, p. 10). 
Circunscreve, nesta concepção de educação do capital, expressa nos documentos dos organismos multilaterais, o real interesse de socializar para o trabalho produtivo explorado, que tem suas origens nos primórdios da sociedade burguesa com Adam Smith. Converte a educação em processos pragmáticos e reducionistas condicionados as exigências do mercado produtivo desde cada nação dentro da divisão internacional do trabalho.

\section{Considerações finaIS}

Para fins de provisórias conclusões, pode-se dizer que neste processo de oferecer diretrizes para reformas educacionais para as nações do chamado terceiro mundo, os organismos multilaterais, essencialmente o Banco Mundial, vincados pelo pressuposto burguês para a educação das massas, convalida seus interesses políticos-ideológicos tendo como substrato o combate e a eliminação da pobreza atrelado à dimensão da segurança, haja vista que consideram a pobreza um risco para desenvolvimento do mercado, salienta Leher (1999).

Essa concepção de educação dos organismos internacionais, têm orientado a política educacional mundialmente, desde o Relatório Jacques Delors "Educação; um Tesouro a descobrir", de 1996 (DELORS, 1998) ao documento intitulado "Aprendizagem para Todos - Estratégia 2020 para a Educação do Grupo Banco Mundial" (BANCO MUNDIAL, 2011). Objetivando disseminar uma concepção de educação que integra os indivíduos na sociedade com vistas à elevação de produtividade e ao desenvolvimento da nova sociabilidade exigida pelo capital. Trata-se de uma concepção empobrecida, meritocrática e neogerencialista, que reduz a formação escolar determinada pelas demandas do capital para formar "necessidades básicas de aprendizagem, competências e habilidades" na formação de recursos humanos - "capital humano", materializada no Brasil na forma da Base Nacional Comum Curricular (BNCC).

Desta forma, atribuem à educação dimensão salvacionista e instrumento chave na reprodução do capital, ao vincular o processo educativo de forma determinada pelas demandas do capital. Portanto, a interface educação e trabalho nesta perspectiva assume um caráter pragmático e unidimensional, inferiorizando o potencial educativo da relação trabalho e educação no viés da formação das múltiplas dimensões do ser humano.

Podemos dizer que os rumos do pensamento pedagógico dos organismos multilaterais são ditados pela lei da divisão social do trabalho para implantar permanentemente em cada nação o projeto societário e os valores da sociabilidade burguesa mundial com vistas a formação para o trabalho subordinado ao capital internacional e, vinte e cinco anos depois, seguimos as mesmas orientações sem termos, efetivamente, permitido o acesso aos trabalhadores àquilo que é próprio à escola - a ciência e o conhecimento sistematizado como riqueza humana.

A possibilidade de se produzir no homem, por meio da educação a humanidade acumulada no tempo histórico, conforme Saviani (2005) se atrela à superação da desumanização própria ao Modo de Produção Capitalista.

\section{REFERÊNCIAS}


BANCO MUNDIAL. Prioridades y estrategias para la educación: Examen del Banco Mundial. Washington, D.C. 1996. Disponível em: http:/www-wds.worldbank.org/external/defaultWDSContentServerWDSP/IB/2005/06/13/000160016_20050613172136/Rendered/PDF/14948010spanish.pdf. Acesso em: 14 dez. 2017.

BANCO MUNDIAL. Relatório №.20475-BR. O Combate à Pobreza no Brasil: Relatório sobre Pobreza, com Ênfase nas Políticas Voltadas para a Redução de Pobreza Urbana. Volume I: Resumo do relatório;31 de março de 2001. Departamento do Brasil - Setor de Redução da Pobreza e Manejo Econômico. Região da américa Latina e Caribe. Disponível em: http://r1.ufrrj.br/geac/portal/wpcontent/uploads/2012/03/Combate_pobreza_urbana.pdf Acesso em: 20 jan. 2017.

DEITOS, Roberto Antônio. Estado, Organismos Internacionais e políticas sociais no Brasil. In: CHAVES, M., SETOGUTI, R. I., VOLSI, M. E. F. (orgs.). A função social da escola: das políticas públicas às práticas pedagógicas. Maringá, PR: Eduem, 2011. 236 p., p. 121-150.

DEITOS, Roberto Antônio. Políticas públicas e educação: aspectos teórico-ideológicos e socioeconômicos. Acta Scientiarum. Education. Maringá, v. 32, n. 2, p. 209-218, 2010. Disponível em: http://periodicos.uem.br/ojs/index.php/ActaSciEduc/article/view/11869/11869. Acesso em: 17 dez. 2015.

DELORS, Jacques (org.). Educação: um tesouro a descobrir. Relatório para UNESCO da Comissão Internacional sobre Educação para o século XXI. Trad.Guilherme João de Freitas Teixeira. Setor de Educação da Representação UNESCO-Brasil, 2010. Disponível em: http://unesdoc.unesco.org/images/0010/001095/109590por.pdf. Acesso em: 20 jan. 2017.

DURKHEIM, Émile. Educação e Sociologia. Tradução de Stephania Matousek. - Petrópolis, RJ: Vozes, 2011.ENGELS, Friedrich. O papel do trabalho na transformação do macaco em homem. 3.ed. São Paulo: Global editora, 1986. 57p. (col. universidade popular)

FRIGOTTO, Gaudêncio, CIAVATTA, Maria. Educação Básica no Brasil na década de 1990: subordinação ativa e consentida à lógica do mercado. Educação e Sociedade., Campinas, vol. 24, n. 82, p. 93-130, abril 2003. Disponível em: http:/www.scielo.br/pdt/es/v24n82/a05v24n82.pdf. Acesso em: 20 jan. 2017.

LEHER, Roberto. Um novo senhor da educação? A política educacional do Banco Mundial para a periferia do capitalismo. Outubro, São Paulo, n. 1, p. 19-30, 1999.

MARX, Karl. O capital: crítica da economia política. Coordenação e revisão de Paul Singer. Tradução de Regis Barbosa e Flávio R. Kothe. São Paulo: Nova Cultural, 1996.

MARX, Karl \& ENGELS, Friedrich. A ideologia alemã. São Paulo: Boitempo,2007.

NEVES, Lúcia Maria Wanderley. PRONKO, Marcela. O mercado do conhecimento e o conhecimento para o mercado: da formação para o trabalho complexo no Brasil contemporâneo - Ri de Janeiro: EPSJV, 2008.

OREALC, Oficina Regional De Educacion Para America Latina Y El Caribe. Boletín 31 Proyecto Principal de Educación para América Latina y el Caribe. UNESCO/OREALC. Agosto/1993. Disponível em: http://unesdoc.unesco.org/images/0009/000952/095252s.pdf. Acesso em: 10 fev. 2016.

PRONKO, Marcela. O Banco Mundial no campo internacional da educação. In: PEREIRA e PRONKO (orgs.). A demolição de direitos: um exame das políticas do Banco Mundial para educação e saúde (19802013). Rio de Janeiro: Escola Politécnica de Saúde Joaquim Venâncio, 2014.

RABELO, Jackeline. SEGUNDO, Maria das Dores Mendes. JIMINEZ, Susana. Educação Para Todos e Reprodução do Capital. In: Revista Trabalho Necessário. Ano 7 - número 9 - 2009. Disponível em: http://www.uff.br/trabalhonecessario/images/TN09\%20JIMENEZ,\%20S.\%20et\%20al.pdf. Acesso em: 05 fev. 2016.

SAVIANI, Dermeval. Pedagogia histórico-crítica: primeiras aproximações. 9.ed. Campinas: Autores Associados, 2005.

SCHULTZ, Theodore William. O Capital Humano: Investimentos em Educação e Pesquisa. Zahar Editores, Rio de Janeiro, 1971.

SHIROMA, Eneida Oto. Política Educacional. Os arautos da Reforma. DP\&A. RJ.2002.

SMITH, Adam. A riqueza das nações (v. 1). São Paulo: Editora Nova Cultural, 1996. 
UNESCO. ORGANIZAÇÕES DAS NAÇÕES UNIDAS PARA A EDUCAÇÃO, CIÊNCIA E CULTURA. Declaração Mundial sobre Educação para Todos: Satisfação das Necessidades Básicas de Aprendizagem, Jomtien, 1990. Brasília: UNESCO, 1990. Disponível em: http:/unesdoc.unesco.org/images/0008/000862/086291por.pdf. Acesso em 07 jan. 2016.

UNESCO. ORGANIZAÇÕES DAS NAÇÕES UNIDAS PARA A EDUCAÇÃO, CIÊNCIA E CULTURA. A Declaração de Nova Delhi sobre Educação Para Todos, Nova Delhi - Índia: Unesco, 1993. Disponível em: http://unesdoc.unesco.org/images/0013/001393/139393por.pdf. Acesso em: 07 jan. 2016.

UNESCO. ORGANIZAÇÕES DAS NAÇÕES UNIDAS PARA A EDUCAÇÃO, CIÊNCIA E CULTURA. Declaração de COCHABAMBA Educação Para Todos: Cumprindo nossos compromissos coletivos. Comitê Intergovernamental Regional do Projeto Principal para a Educação (PROMEDLAC VII), Cochabamba, Bolívia, março de 2001. Disponível em: http://unesdoc.unesco.org/images/0012/001275/127510por.pdf. Acesso em 25 jan. 2016.

UNESCO. ORGANIZAÇÕES DAS NAÇÕES UNIDAS PARA A EDUCAÇÃO, CIÊNCIA E CULTURA. Educação Para Todos: o compromisso de Dakar, Senegal: Cúpula Mundial de Educação, 2001. Disponível em: http://unesdoc.unesco.org/images/0012/001275/127509porb.pdf. Acesso em: 14 jan. 2016.

WILLIAMSON, John. Reformas políticas na América Latina na década de 80. In: Revista de Economia Política. São Paulo: Brasiliense, vol.12, n. 1 (45), janeiro-março/1992, p. 43-51

Data da submissão: 17/10/2020.

Data da aprovação: 15/03/2021. 